\title{
Differing preferences of Antarctic soil nematodes for microbial prey
}

Kevin K. Newsham*, Jochen Rolf, David A. Pearce and Rodney J. Strachan

British Antarctic Survey, Natural Environment Research Council, High Cross, Madingley Road, Cambridge, U.K.

* Corresponding author. Fax: +44-1223-362616

E-mail address: kne@bas.ac.uk

Running title: Feeding preferences of Antarctic soil nematodes

\begin{abstract}
We tested the preferences of three nematode taxa, Geomonhystera villosa, Plectus spp. and Teratocephalus spp., extracted from moss at Signy Island in the Maritime Antarctic, for two microalgae, three microfungi and six heterotrophic bacteria, each also from soils at Signy Island. Choice test experiments on water agar medium, in which nematodes were enumerated in wells containing microbes at 24 and $48 \mathrm{~h}$, indicated that there were differing preferences between nematodes for distinct prey. G. villosa was significantly attracted to the alga Chlorella $\mathrm{cf}$. minutissima and the fungus Mortierella hyalina, and was more attracted to all algae and fungi than either of the other two nematodes. Both G. villosa and Teratocephalus spp. were attracted to an actinobacterium. Plectus spp. were significantly attracted to the alga Stichococcus bacillaris and bacteria with close taxonomic affinities to Arthrobacter, Pseudomonas and Polaromonas. Experiments using $0.5 \mu \mathrm{m}$ diameter fluorescent beads indicated significantly increased ingestion by nematodes in the presence of each of these microbes compared with controls, except by Plectus spp. in the presence of S. bacillaris. We conclude that complex trophic interactions may occur in apparently simple Antarctic soil food webs.
\end{abstract}

Key words: Algae / bacteria / food webs / fungi / trophic interactions 


\section{Introduction}

Nematodes are dominant components of Antarctic soil food webs. Not only are they abundant, with up to $10^{6}$ individuals present per $\mathrm{m}^{2}$ of soils in the Maritime Antarctic [11], but they also play important ecological roles in these soils by acting as consumers, typically of bacterial prey, and also as predators of other nematodes, rotifers and protozoa [21]. Furthermore, nematodes are the top predators in what are thought to be the simplest soil food webs encountered on Earth, those occurring in the McMurdo Dry Valleys of Continental Antarctica [7]. Previous studies have concentrated on Antarctic nematode taxonomy, ecophysiology and biogeography $[2,7,10,11,15,26]$. However, despite their potentially large ecological influence, little is known of the feeding preferences of Antarctic soil nematodes [11]. Direct observations suggest that a species of Mesodorylaimus at Signy Island in the Maritime Antarctic may feed upon coccoid algae and dead collembola [21]. Coomansus gerlachei has also been shown to feed upon algae, fungal hyphae and spores, arthropods, rotifers and tardigrades in Signy Island soil [21]. Furthermore, laboratory studies have shown that a yeast and bacteria isolated from the McMurdo Dry Valleys support the growth of Scottnema lindsayae Timm. extracted from the same habitat [14]. However this is the only information available on the specific feeding preferences of Antarctic soil nematodes.

Here we report a study which aimed to determine the preferences of the three most abundant soil nematode taxa at Signy Island, viz. Geomonhystera villosa (Bütschli) Andrássy, Plectus spp. and Teratocephalus spp., for 11 microbes, each isolated from Signy Island soil. These nematodes are currently classified as microbivores and are assumed to feed predominantly on bacteria, although their diet might potentially include algae and filamentous fungi [21]. We also tested for significant differences between nematodes' preferences for microbes to assess whether apparently simple Antarctic soil food webs consist of complex patterns of trophic interactions.

\section{Methods}

\subsection{Extraction of nematodes}

Nematodes were extracted from turves of the moss Sanionia uncinata (Hedw.) Loeske ex Nitardy collected from $100 \mathrm{~m}$ to the east of the British Antarctic Survey's research station on Signy Island $\left(60^{\circ}\right.$ $42^{\prime} 34^{\prime \prime} \mathrm{S}, 45^{\circ} 35^{\prime} 36^{\prime \prime} \mathrm{W}$ ) in austral summer 2001 . The moss was frozen at $-20^{\circ} \mathrm{C}$ shortly after collection and was transported to the UK. Small (c. $5 \mathrm{~g}$ fresh weight) pieces of frozen moss were placed 
onto muslin resting on a $2 \mathrm{~mm}$ rigid mesh in the mouth of a plastic funnel held by a retort stand. A plastic tube attached to the funnel's spout was blocked with a clip and spring water was added to the funnel until a thin layer covered the moss. Nematodes that passed through the muslin were collected after $24 \mathrm{~h}$ by releasing the clip. They were sorted under a dissecting microscope (6-50 x magnification) into G. villosa, Plectus spp. (typically P. antarcticus de Man) and Teratocephalus spp. (typically $T$. tilbrooki Maslen) and were stored in spring water at $4{ }^{\circ} \mathrm{C}$ for a maximum of $3 \mathrm{~d}$ until required for experiments.

\subsection{Isolation of microbes from soil}

Microbes were isolated from soil under $S$. uncinata taken from the same location at which moss was collected for nematode extraction. Microalgae were isolated on Bold's Basal (BB) medium (SigmaAldrich, St Louis, MO, U.S.A.). Dilution series of $1 \mathrm{~g}$ (fresh weight) of soil were prepared in sterile 10 $\mathrm{mM}$ phosphate buffer, $100 \mu \mathrm{l}$ aliquots of the $10^{-4}$ dilution were spread onto BB medium in $90 \mathrm{~mm}$ single vented Petri dishes and the dishes were incubated in the light at $c .4{ }^{\circ} \mathrm{C}$. A single colony of the alga Stichococcus bacillaris Nag., and two separate colonies of the alga Chlorella cf. minutissima, were isolated onto BB medium after $28 \mathrm{~d}$ and were kept in the light at $4{ }^{\circ} \mathrm{C}$ until required for experiments. Algal isolates were free of bacteria. The shapes and dimensions of each alga are shown in Table 1.

Microfungi were isolated by a modification of the Warcup soil plate method [24]. Briefly, small volumes of soil (c. $5 \mathrm{mg}$ fresh weight) were placed into non-vented $90 \mathrm{~mm}$ Petri dishes, cooled broad-spectrum Czapek-Dox agar medium was placed onto the soil and the dishes were incubated at 4 ${ }^{\circ} \mathrm{C}$ for $21 \mathrm{~d}$. Single colonies of the three commonest fungi, Mortierella hyalina (Harz) W. Gams, Penicillium aurantiogriseum Dierckx. and Trichoderma viride Pers.: Fr., were isolated onto potato dextrose agar medium and kept at $4{ }^{\circ} \mathrm{C}$ until required for experiments. The shapes and dimensions of the conidia of each fungus are shown in Table 1.

Bacteria were isolated on R2A (Oxoid Ltd., Basingstoke, U.K.), a broad spectrum bacteriological agar medium. Dilution series of soil were prepared as for algae, and $100 \mu$ l aliquots of the $10^{-4}$ dilution were spread onto the medium in $90 \mathrm{~mm}$ single vented Petri dishes. The dishes were incubated in the dark at $4{ }^{\circ} \mathrm{C}$ and individual colonies of the commonest six morphotypes of bacteria were isolated onto R2A medium after $28 \mathrm{~d}$. 


\subsection{Taxonomic placement of bacteria}

Bacteria were taxonomically placed by comparing $16 \mathrm{~S}$ rRNA sequences with those in a public access database. A single colony of each isolate was placed in $50 \mu \mathrm{l}$ of sterile water. Cells were then vortexed and subjected to five freeze-thaw cycles $\left(-80^{\circ} \mathrm{C}\right.$ and $80^{\circ} \mathrm{C}$, each for $\left.2 \mathrm{~min}\right)$. The resulting supernatant was cleaned for polymerase chain reaction (PCR) amplification with GFX DNA purification columns (Amersham Biosciences U.K. Ltd., Chalfont St Giles, U.K.).

PCR amplification was performed using $43 \mu \mathrm{l}$ of ABgene 1.1x ReddyMix PCR Master Mix (ABgene, Epsom, U.K.) with 20 pmole of each primer and c. $10 \mathrm{ng}$ of template DNA in a final volume of $50 \mu \mathrm{l}$. The amplification program consisted of one cycle of $95^{\circ} \mathrm{C}$ for $5 \mathrm{~min}, 30$ cycles of $94{ }^{\circ} \mathrm{C}$ for 1 $\min , 56^{\circ} \mathrm{C}$ for $1 \mathrm{~min}, 72^{\circ} \mathrm{C}$ for $70 \mathrm{sec}$ and a final extension step of $72{ }^{\circ} \mathrm{C}$ for $10 \mathrm{~min}$. Bacterial rDNA was targeted with the primers 8F (5'-AGAGTTTGATCCTGGCTCAG-3') [6] and 1500R (5'-

AGAAAGGAGGTGATCCAGCC-3') [4]. PCR products were purified using GFX DNA purification columns and sequenced. Sequence reactions were run on a Megabace 500 sequencer (Amersham Biosciences U.K. Ltd.) using the $8 \mathrm{~F}$ primer. Nucleotide sequences obtained from the bacteria have been deposited in the EMBL Nucleotide Sequence database (http://www.ebi.ac.uk/embl). The accession numbers of the deposited sequences are AJ557831, AJ557832, AJ557833, AJ557834, AJ557835 and AJ557836. The bacteria from which these sequences were obtained are hereafter referred to as B1, B3, B6, B7, B9 and B16, respectively. The closest phylogenetic affiliations of the bacteria to named species or genera in the EMBL database are shown in Table 1, along with cell shapes and dimensions.

\subsection{Preference experiment}

Nematodes were offered a choice of microbes in a 'cafeteria' design [23] on lake water agar (LWA) medium. The medium consisted of $0.2 \mu \mathrm{m}$-filtered water from an oligotrophic lake at Signy Island, 0.5\% technical agar (agar no.3, Oxoid Ltd., Basingstoke, U.K.) and $50 \mu \mathrm{g} \mathrm{ml}^{-1}$ of the bacteriostatin ampicillin (Sigma-Aldrich, Gillingham, U.K.). Preliminary experiments indicated that ampicillin added to the LWA medium reduced bacterial growth on its surface and improved attraction of nematodes to microbial prey offered within the cafeteria design, relative to LWA medium without ampicillin. These experiments also indicated that the inclusion of ampicillin in the medium was more effective at reducing bacterial growth than rinsing nematodes in bacteriostatin solution prior to preference experiments [12]. With the regular addition of bacteria to cultures, nematodes could be kept for at least 
four weeks on LWA medium to which ampicillin had been added without showing altered behaviour, reproduction or mortality. The LWA medium was poured to a depth of $1.5 \mathrm{~mm}$ into 48 single-vented $90 \mathrm{~mm}$ Petri dishes. After the layer of LWA medium had solidified, six sterile plastic cylinders of 12 $\mathrm{mm}$ diameter and $15 \mathrm{~mm}$ length were placed vertically and equidistantly onto the medium under a sterile hood. The centre of each disk was $30 \mathrm{~mm}$ from the centre of the Petri dish. A second layer of LWA medium was then gently poured to a depth of $5 \mathrm{~mm}$. After this layer of medium had solidified the plastic cylinders were removed, leaving six wells of $12 \mathrm{~mm}$ diameter and $5 \mathrm{~mm}$ depth in the LWA medium (Fig. 1 a).

Three alternate wells in each Petri dish were plugged with $12 \mathrm{~mm}$ diameter and c. $4.5 \mathrm{~mm}$ thick discs of R2A medium. These wells are hereafter referred to as control wells. The remaining three wells were plugged with discs of R2A medium (Fig. 1 b), of the same dimensions as those in control wells, on which microbes had been grown for $7 \mathrm{~d}$ in the light at $15^{\circ} \mathrm{C}$. Twelve Petri dishes received alternate plugs inoculated with C. minutissima strains 1 and 2 and S. bacillaris, 12 dishes received alternate plugs inoculated with $M$. hyalina, $P$. aurantiogriseum and $T$. viride, 12 dishes received alternate plugs inoculated with B1, B3 and B6, and a further 12 dishes received alternate plugs inoculated with B7, B9 and B16. Hyphae and conidia were present on the plugs of medium on which fungi were grown. The total volumes of cells offered to nematodes, estimated from the product of the mean volume of each cell (calculated from standard geometric formulae, assuming right circular cylinders for rods and spheres for cocci) and the mean number of cells per unit area of medium from which plugs were cut, did not differ within each of the three groups of microbes (all $P>0.05$ ). There was also no difference between the total cell volumes \pm s.e.m. of algae and bacteria in each well (29.5

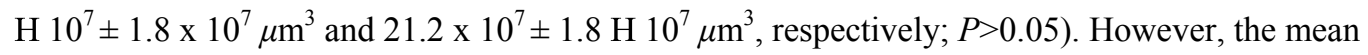
volume \pm s.e.m. of fungal hyphae and conidia $\left(c .7 .4 \times 10^{7} \pm 1.2 \times 10^{7} \mu \mathrm{m}^{3}\right)$ in each well was significantly lower than the volumes of algal and bacterial cells presented to nematodes $(P<0.01)$. After the plugs of medium had been added to each of the 48 dishes, the LWA medium was gently flooded with a $c .1 \mathrm{~mm}$ deep layer of $0.2 \mu \mathrm{m}$-filtered lake water to ensure that less motile nematodes could move across the agar medium surface. The tops of the R2A medium plugs were c. 0.5 $\mathrm{mm}$ lower than the level of LWA medium in each Petri dish, ensuring that excess microbial cells did not distribute across the surface of the medium when the layer of lake water was added. Groups of 50 adult $G$. villosa, Plectus spp. or Teratocephalus spp. of similar size, each of which had been washed in 
three changes of sterile lake water, were pipetted into the water at the centre of each of four Petri dishes containing plugs of R2A agar medium inoculated with either algae, fungi or one of the two combinations of bacteria. The dishes were incubated in the dark at $15{ }^{\circ} \mathrm{C}$ to ensure rapid movement of nematodes towards microbial prey [12]. Nematodes in each well were counted at 24 and $48 \mathrm{~h}$ with a stereomicroscope (6-50 x magnification). The dishes were handled carefully to avoid displacement of nematodes from the wells.

\subsection{Ingestion of fluorescent beads}

When the preference experiment indicated significant attraction of nematodes to microbes, experiments using fluorescent beads were performed to test for increased ingestion by nematodes in the presence of prey. Spring water $(0.2 \mu \mathrm{m}$-filtered) was added to a depth of $1 \mathrm{~mm}$ to colonies of the appropriate microbes growing on R2A medium and the surfaces of the colonies were gently rubbed with a sterile glass spreader. Aliquots $(0.5 \mathrm{ml})$ of the water, containing c. $2.5 \times 10^{6}$ algal and bacterial cells and c. 1.2 x $10^{6}$ fungal conidia, were dispensed into tissue culture plate wells and $2 \mu \mathrm{l}$ of a suspension of Tetraspeck fluorescent beads ( $0.5 \mu$ m diameter; Molecular Probes Inc., Eugene, OR, U.S.A.), with respective excitation and emission maxima at 505 and $515 \mathrm{~nm}$, was added to each well. Controls consisted of $0.5 \mathrm{ml}$ of $0.2 \mu \mathrm{m}$-filtered spring water, taken from the surface of uninoculated R2A medium, with $2 \mu$ of fluorescent beads suspension. Treatment and control wells each received c. $3 \mathrm{x}$ $10^{6}$ beads. Individual nematodes were introduced into each of 10 control and treatment wells and the tissue culture plates were incubated in the dark at $15^{\circ} \mathrm{C}$. The number of fluorescent beads ingested by each nematode was counted after $24 \mathrm{~h}$ using epifluorescence at $1000 \mathrm{x}$ magnification.

\subsection{Statistical analyses}

One way ANOVA was used to compare (i) the numbers of nematodes remaining on the agar medium surface with those accumulated in control wells and wells containing microbial prey and (ii) the numbers of nematodes accumulated in control wells with those accumulated in wells containing microbial prey. Control values entered into the latter analyses were the mean numbers of nematodes in the two control wells either side of each replicate well containing the appropriate microbial prey. Repeated measures ANOVA was used to determine the main effects of time, and the main and interactive effects of prey type and nematode genus or species, on nematode accumulation in wells. 
Control values were eliminated from these analyses. One way ANOVA was also used to compare the numbers of fluorescent beads accumulated in the guts of nematodes in the presence of microbial prey with the numbers accumulated in the guts of nematodes in water controls.

\section{Results}

\subsection{Responses to time}

No main effect of time was found on the numbers of nematodes accumulated in wells containing microbial prey (Table 2): numbers of nematodes in the wells remained the same at 24 and $48 \mathrm{~h}$.

\subsection{Responses to algae}

Significantly more nematodes remained on the LWA medium surface than accumulated in control wells and wells containing algae (mean numbers per dish $=35.4$ and 14.6 , respectively; $P<0.001$ ). However, there was a strong main effect of algae on nematode accumulation in wells (Table 2): more nematodes accumulated in wells containing C. minutissima strain 2 than in wells containing $C$. minutissima strain 1 or $S$. bacillaris (mean numbers per well \pm s.e.m. $=4.5 \pm 0.7,1.5 \pm 0.2$ and $2.6 \pm$ 0.4 , respectively). There was also a highly significant main effect of nematode genus on the numbers of nematodes accumulated in wells containing algae (Table 2): G. villosa was more frequently recorded in algal wells than Plectus spp. or Teratocephalus spp. (mean numbers per well \pm s.e.m. $=4.8 \pm 0.7,2.5 \pm$ 0.3 and $1.3 \pm 0.3$, respectively). Furthermore, there was a significant interactive effect of alga and nematode genus on the numbers of nematodes accumulated in wells (Table 2): there were significant differences between nematode genera in the isolates of algae that they were attracted to.

A comparison of the mean numbers of nematodes accumulated in wells containing individual algae with those in adjacent control wells indicated significant attraction to two algal isolates. $G$. villosa was significantly attracted to C. minutissima strain 2 and Plectus spp. were attracted to $S$. bacillaris (Fig. 2 a, b). However only G. villosa ingested a significantly greater number of fluorescent beads in the presence of algal cells compared with water controls (Fig. 2 a, inset): Plectus spp. did not ingest more beads when presented with S. bacillaris (Fig. 2 b, inset). 


\subsection{Responses to fungi}

Significantly more nematodes remained on the LWA medium surface than accumulated in control wells and wells containing fungi (mean numbers per dish $=38.3$ and 11.7 , respectively; $P<0.001$ ). There was also no main effect of different fungi on nematode accumulation in wells (Table 2). However there was a strong main effect of nematode genus on the numbers of nematodes accumulated in wells containing fungi (Table 2): more G. villosa individuals were attracted to wells containing fungi than either Plectus spp. or Teratocephalus spp. (mean numbers per well \pm s.e.m. $=4.0 \pm 0.6,2.4 \pm 0.3$ and $1.0 \pm 0.2$, respectively). There was no interactive effect of fungus and nematode genus on the numbers of nematodes accumulated in wells containing fungi (Table 2). Only one significant trophic link between nematodes and fungi was recorded: $G$. villosa was significantly attracted to $M$. hyalina (Fig. 2 c) and ingested a greater number of fluorescent beads compared with controls when presented with conidia of the fungus (Fig. 2 c, inset).

\subsection{Responses to bacteria}

There was no difference between the numbers of nematodes remaining on the LWA medium surface and those accumulated in control wells and wells containing bacteria (mean numbers per dish $=28.0$ and 22.0, respectively, $P>0.05$ ). There were no significant main effects of bacterium or nematode genus on the accumulation of nematodes in wells (Table 2). However, there was a strong interactive effect of bacteria and nematode genus on nematode accumulation in wells (Table 2): there were significant differences between nematode genera in the isolates of bacteria that they were attracted to.

A comparison of the numbers of nematodes accumulated in wells containing individual bacteria with those accumulated in adjacent control wells indicated that both G. villosa and Teratocephalus spp. were attracted to B16 (Fig. 2 d, e). Both of these nematodes ingested more fluorescent beads in the presence of B16 than in their absence (Fig. $2 \mathrm{~d}$, e insets). Higher numbers of Plectus spp. accumulated in wells containing B3, B7 and B9 than accumulated in control wells (Fig. 2 $\mathrm{f}-\mathrm{h}$ ) and more fluorescent beads were ingested by Plectus spp. in the presence of these bacteria than in their absence (Fig. 2 f-h, insets). 


\section{Discussion}

Our experiments indicated significant differences between nematodes in the algal and bacterial prey that they were attracted to. The finding that Antarctic soil nematodes exhibited differing preferences for microbial prey is an important observation because it suggests that they are apparently not generalist feeders, as has been previously assumed [21]. Selective, rather than generalist, feeding by nematodes on microbial prey may have important implications for analysing the flow of energy through soil food webs, particularly if microbivorous nematodes do not specifically feed on bacteria or fungi, as has been assumed in previous work [14]. Furthermore, selective feeding by nematodes on microbial prey may alter the outcome of interspecific competition between microbes and potentially has implications for determining microbial distribution in soil. Differing preferences for microbial prey have similarly been shown in marine ecosystems, in which different nematode species have been shown to exhibit selective preferences for distinct diatoms and bacteria [12,23]. These differences in the attraction of nematodes to distinct microbial species, and, in the case of Geomonhystera in the current study, to specific strains of microbes, are likely to be owing to chemotaxis towards different types or concentrations of watersoluble compounds produced by microbes, such as cyclic nucleotides or ammonia $[3,25]$.

The laboratory-based approach taken in this study was necessary to determine trophic interactions between members of a soil microbial food web. However the artificial nature of the experiments probably influenced nematode response to microbial prey. For example, the use of a twodimensional agar medium surface on which to offer prey to nematodes may have influenced their behaviour, relative to the three dimensional matrix in which they locate prey in the natural environment [1]. The growth of prey on a relatively nutrient-rich medium is also likely to have altered their attractiveness to nematodes, relative to prey growing in nutrient-limited conditions in soil. Furthermore, a relatively high temperature $\left(15^{\circ} \mathrm{C}\right)$ was used in our experiments to ensure rapid movement of nematodes towards microbial prey. This temperature is regularly experienced by organisms inhabiting the upper layers of Antarctic soils during cloudless periods in summer, but does not persist for more than a few hours each day [9]. A previous study has, however, found that temperature does not influence nematode preference for different microbial prey [23].

Another artificial aspect of our study was the inclusion of a bacteriostatin in the agar medium used in the preference experiment. It was necessary to use the bacteriostatin because bacterial contaminants present on the surfaces of nematodes, which had been extracted directly from field- 
collected material, grew on the agar medium and reduced the attraction of nematodes to microbes in wells. Previous studies [12,23] have not adopted this approach, probably because nematodes were extracted from long-term gnotobiotic cultures fed on specific strains of bacteria or diatoms, reducing the numbers of contaminants present on nematodes. However, we were unable to adopt this approach in our experiments: although we have developed cultures of Plectus spp. from Signy Island soil, we have failed to develop either G. villosa or Teratocephalus spp. cultures, despite repeated attempts to do so.

Despite the artificial experimental conditions used in our study, common elements of the microbial food web present in Signy Island soil were used in the experiments. Previous work has found $70 \%$ of nematodes extracted from moss at the island to consist of $G$. villosa and species of Plectus and Teratocephalus [11]. Furthermore, the microbial prey presented to nematodes in our study are commonly present in the natural environment. For example, S. bacillaris, Arthrobacter, Bacillus, Chlorella and Mortierella spp. are all frequently isolated from Signy Island soils [5,8]. S. bacillaris, Chlorella and Mortierella spp. are also common representatives of eukaryotic rDNA clone libraries constructed from Signy Island soil (B. Lawley, pers. comm.). In addition, the numbers of microbial cells offered to nematodes in our study were similar to those encountered in the field: algal and bacterial cell counts at soil surfaces range from $1 \times 10^{3}$ to $8.5 \times 10^{6} \mathrm{~cm}^{-2}$ and $4 \times 10^{9}$ to $3 \times 10^{10} \mathrm{~cm}^{-2}$, respectively [5,20], which broadly correspond to the mean numbers of cells of these microbes presented to nematodes in our study $\left(1.1 \times 10^{7}\right.$ and $7.0 \times 10^{8} \mathrm{~cm}^{-2}$, respectively).

Our data in part confirm current views on the feeding habits of Antarctic nematodes. Plectus spp. and Teratocephalus spp. are typically classified as bacterial feeders [27] and our study suggested that these nematodes only feed upon bacteria, and not on algae and fungi. However, Geomonhystera spp. are classified as bacterial feeders and substrate ingesters [27] and our data indicate that G. villosa should now also be classed as a unicellular eukaryote feeder in the scheme presented by Yeates et al. [27]. Given that G. villosa has wider mouthparts than Plectus spp. or Teratocephalus spp. (mean stoma widths of the nematodes are $c .7,5$ and $3 \mu \mathrm{m}$, respectively [2,10]), it is not surprising that it was more attracted to algae and fungi than the other two nematodes: with the exception of the bacterium B1, algal and fungal cells were larger than the bacteria offered to nematodes.

Previous studies have recorded heterogeneous spatial distributions of nematodes in Antarctic soils $[11,18]$. The primary factors responsible for these clumped distributions are thought to be 
increased temperature and water availability, which lead to the development of favourable microhabitats for nematodes in soil $[11,18]$. However, discrete microhabitats in soils also favour the development of distinct microbial populations, for example by affinities for different organic substrates [21]. In agreement with previous studies $[11,16,18,19]$, our data therefore suggest that attraction to different populations of microbial prey present in discrete microhabitats may be a potentially important factor governing the heterogeneous distribution of nematodes in Antarctic soils.

Our observation that nematodes exhibited differing preferences for microbial prey suggests that complex trophic interactions may exist in apparently simple Antarctic soil food webs. This observation has potentially important implications for predicting the responses of these food webs to imminent climate change. The simplicity of food webs in Antarctic soils, and particularly those of Continental Antarctica, is thought to increase their vulnerability to environmental change [7]. However, given the strong theoretical link between resilience to perturbation and food web complexity, and in particular connectance [17], the finding that these food webs may exhibit reduced connectance is likely to influence their response to environmental change. At present it is not possible to accurately predict whether low connectance within Antarctic soil food webs increases or decreases their resilience to perturbation. This question, and the influence of other aspects of food web architecture on the response of model Antarctic food webs to environmental change, is a focus for ongoing research in our laboratory.

\section{Acknowledgements}

Funding from the Natural Environment Research Council through the British Antarctic Survey's Terrestrial and Freshwater Biodiversity project is gratefully acknowledged. Drs Z. Lawrence. P. Kirk and A. Lukesova kindly identified the $P$. aurantiogriseum, $M$. hyalina and algal isolates, respectively. Rolf Maslen, Tobias Garstecki and two anonymous referees supplied useful comments on the manuscript. 


\section{References}

[1] A.R.A. Anderson, I.M. Young, B.D. Sleeman, B.S. Griffiths, W.M. Robertson, Nematode movement along a chemical gradient in a structurally heterogeneous environment. I. Experiment, Fundam. Appl. Nematol. 20 (1997) 157-163.

[2] I. Andrássy, Nematodes in the sixth continent, J. Nematode Syst. Morphol. 1 (1998) 107-186.

[3] P.A. Andrew, W.L. Nicholas, Effect of bacteria on dispersal of Caenorhabditis elegans (Rhabditidae), Nematologica 22 (1976) 451-461.

[4] E. Brambilla, H. Hippe, A. Hagelstein, B. Tindall, E. Stackebrandt, 16S rDNA diversity of cultured and uncultured prokaryotes of a mat sample from Lake Fryxell, McMurdo Dry Valleys, Antarctica, Extremophiles 5 (2001) 23-33.

[5] P.A. Broady, Quantitative studies on the terrestrial algae of Signy Island, South Orkney Islands, Br. Antarct. Surv. Bull. 47 (1979) 31-41.

[6] J. Dunbar, S. Takala, S.M. Barns, J.A. Davis, C.R. Kuske, Levels of bacterial community diversity in four arid soils compared by cultivation and 16S rRNA gene cloning, Appl. Env. Microbiol. 65 (1999) 1662-1669.

[7] D.W. Freckman, R.A. Virginia, Low-diversity Antarctic soil nematode communities: distribution and response to disturbance, Ecology 78 (1997) 363-369.

[8] O.W. Heal, A.D. Bailey, P.M. Latter, Bacteria, fungi and protozoa in Signy Island soils compared with those from a temperate moorland, Phil. Trans. Royal Soc. Lond. B 252 (1967) 191-197.

[9] R.E. Longton, M.W. Holdgate, Temperature relationships of Antarctic vegetation, Phil. Trans. Royal Soc. Lond. B 252 (1967) 237-250. 
[10] N.R. Maslen, Six new nematode species from the Maritime Antarctic, Nematologica 25 (1979) 288-308

[11] N.R. Maslen, The Signy Island terrestrial reference sites: XII. Population ecology of nematodes with additions to the fauna, Brit. Antarct. Surv. Bull. 53 (1981) 57-75.

[12] T. Moens, L. Verbeeck, A. de Maeyer, J. Swings, M. Vincx, Selective attraction of marine bacterivorous nematodes to their bacterial food, Mar. Ecol. Prog. Ser. 176 (1999) 165-178.

[13] J.C. Moore, H.W. Hunt, Resource compartmentation and the stability of real ecosystems, Nature 333 (1988) 261-263.

[14] A. Overhoff, D.W. Freckman, R.A. Virginia, Life cycle of the microbivorous Antarctic Dry Valley nematode Scottnema lindsayae (Timm 1971), Polar Biol. 13 (1993) 151-156.

[15] J. Pickup, P. Rothery, Water loss and anhydrobiotic survival in nematodes of Antarctic fellfields, Oikos 61 (1991) 379-388.

[16] J.K. Pillai, D.P. Taylor, Influence of fungi on host preference, host suitability, and morphometrics of five mycophagous nematodes, Nematologica 13 (1967) 529-540.

[17] S.L. Pimm, The complexity and stability of ecosystems, Nature 307 (1984) 321-326.

[18] L.E. Powers, D.W. Freckman, R.A. Virginia, Spatial distribution of nematodes in polar desert soils of Antarctica, Polar Biol. 15 (1995) 325-333.

[19] L. Ruess, E.J.G. Zapata, J. Dighton, Food preferences of a fungal-feeding Aphelenchoides species, Nematology 2 (2000) 223-230. 
[20] H.G. Smith, P.V. Tearle, Aspects of microbial and protozoan abundances in Signy Island fellfields, Brit. Antarct. Surv. Bull. 68 (1985) 83-90.

[21] V.W. Spaull, Distribution of nematode feeding groups at Signy Island, South Orkney Islands, with an estimate of their biomass and oxygen consumption, Brit. Antarct. Surv. Bull. 37 (1973) 21-32.

[22] M.J. Swift, Species diversity and the structure of microbial communities in terrestrial habitats, in: J.M. Anderson, A. Macfadyen (Eds.), The role of terrestrial and aquatic organisms in decomposition processes, Blackwell, 1976, pp. 185-222.

[23] D.B. Trotter, J.M. Webster, Feeding preferences and seasonality of free-living marine nematodes inhabiting the kelp Macrocystis integrifolia, Mar. Ecol. Prog. Ser. 14 (1984) 151-157.

[24] J.H. Warcup, The soil plate method for the isolation of fungi from soil, Nature 166 (1950) 117118.

[25] S. Ward, Chemotaxis of the nematode Caenorhabditis elegans: identification of attractants and analysis of the response by use of mutants, Proc. Nat. Ac. Sci. USA 70 (1973) 817-821.

[26] D.A. Wharton, W. Block, Freezing tolerance in some Antarctic nematodes, Funct. Ecol. 7 (1993) 578-584.

[27] G.W. Yeates, T. Bongers, R.G.M. Degoede, D.W. Freckman, S.S. Georgieva, Feeding habits in soil nematode families and genera - an outline for soil ecologists, J. Nematol. 25 (1993) 315-331. 
Table 1

Taxonomic placement and morphology of microbial prey

\begin{tabular}{|c|c|c|c|c|}
\hline prey type & name & shape & $\begin{array}{l}\text { length of rod / } \\
\text { diameter of } \\
\text { coccus }(\mu \mathrm{m})^{\mathrm{a}}\end{array}$ & $\begin{array}{l}\text { width of rod } \\
(\mu \mathrm{m})^{\mathrm{a}}\end{array}$ \\
\hline \multirow[t]{3}{*}{ alga } & Chlorella cf. minutissima strain 1 & coccus & $3.0-(3.7)-8.0$ & \\
\hline & Chlorella cf. minutissima strain 2 & coccus & $3.0-(4.0)-7.0$ & \\
\hline & Stichococcus bacillaris & rod & $3.0-(5.6)-10.0$ & $2.0-(2.1)-3.0$ \\
\hline \multirow[t]{3}{*}{ fungus } & Mortierella hyalina & $\operatorname{coccus}^{b}$ & $4.0-(4.7)-5.5$ & \\
\hline & Penicillium aurantiogriseum & $\operatorname{coccus}^{b}$ & $2.8-(3.0)-3.5$ & \\
\hline & Trichoderma viride & $\operatorname{coccus}^{b}$ & $3.0-(3.1)-3.5$ & \\
\hline \multirow[t]{6}{*}{ bacterium } & 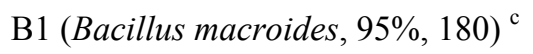 & rod & $6.0-(23.3)-80.0$ & 1.2 \\
\hline & B3 $\left(\right.$ Arthrobacter, 99\%, 720) ${ }^{\mathrm{c}}$ & rod & $0.8-(1.0)-1.2$ & 0.5 \\
\hline & B6 (Frateuria, 95\%, 754) ${ }^{\mathrm{c}}$ & rod & $1.0-(1.2)-1.8$ & 0.3 \\
\hline & B7 (Pseudomonas, 98\%, 684) ${ }^{\mathrm{c}}$ & rod & $1.0-(1.5)-2.0$ & 0.4 \\
\hline & B9 $(\text { Polaromonas, } 98 \%, 659)^{\mathrm{c}}$ & rod & $1.0-(1.2)-1.5$ & 0.3 \\
\hline & B16 (Frigoribacter, 90\%, 670) ${ }^{\mathrm{c}}$ & rod & $0.5-(0.6)-0.8$ & 0.2 \\
\hline
\end{tabular}

${ }^{\mathrm{a}} n=50$, values are minimum-(mean)-maximum, except for widths of bacteria which are approximate values

b conidia only

${ }^{\mathrm{c}}$ names, percentages and numbers in parentheses are the closest phylogenetic affiliations of bacteria to named species or genera, the similarities to these taxa and the sequence length in base pairs 
Table 2

Main effects of time, and main and interactive effects of prey type and nematode genus, on the numbers of nematodes accumulated in wells containing microbial prey in preference experiment. Data were analysed by repeated measures ANOVA.

\begin{tabular}{|c|c|c|c|c|}
\hline main and interactive effects & d.f. & $F$ & $P$ & \\
\hline time & 1,27 & 2.16 & 0.154 & \\
\hline alga & 2,27 & 14.36 & $<0.001$ & $* * *$ \\
\hline nematode & 2,27 & 19.74 & $<0.001$ & $* * *$ \\
\hline alga $\mathrm{x}$ nematode & 4,27 & 8.91 & $<0.001$ & $* * *$ \\
\hline time & 1,27 & 2.17 & 0.152 & \\
\hline fungus & 2,27 & 0.40 & 0.676 & \\
\hline nematode & 2,27 & 5.95 & 0.007 & $* *$ \\
\hline fungus $\mathrm{x}$ nematode & 4,27 & 0.44 & 0.776 & \\
\hline time & 1,60 & 1.51 & 0.233 & \\
\hline bacterium & 5,60 & 1.75 & 0.138 & \\
\hline nematode & 2,60 & 0.55 & 0.582 & \\
\hline bacterium $\mathrm{x}$ nematode & 10,60 & 3.42 & $<0.001$ & $* * *$ \\
\hline
\end{tabular}




\section{Figure legends}

Fig. 1. (a) Transverse section through Petri dish used in the preference experiment (b) Plan view of dish showing positions of control wells $(\bigcirc)$ and wells containing microbial prey (®).

Fig. 2. Numbers of nematodes accumulated in control wells ( $\square$ ) and wells containing microbial prey (Ш) in the preference experiment. Nematode / prey combinations are shown above each Figure.

Values are means of four replicates \pm s.e.m. Data in (b), (d) and (f) were recorded at $24 \mathrm{~h}$, data in other Figures were recorded at $48 \mathrm{~h}$. Note that $y$-axes of all Figures are identically scaled. Insets: numbers of fluorescent beads ingested per nematode in the absence $(\square)$ and presence $(\mathbb{\$})$ of prey. Values are means of 10 replicates \pm s.e.m. Differences between control and treatment means in Figures and insets are indicated by n.s. $P>0.05 ; * P<0.05 ; * * P<0.01 ; * * * P<0.001$. 
(a)
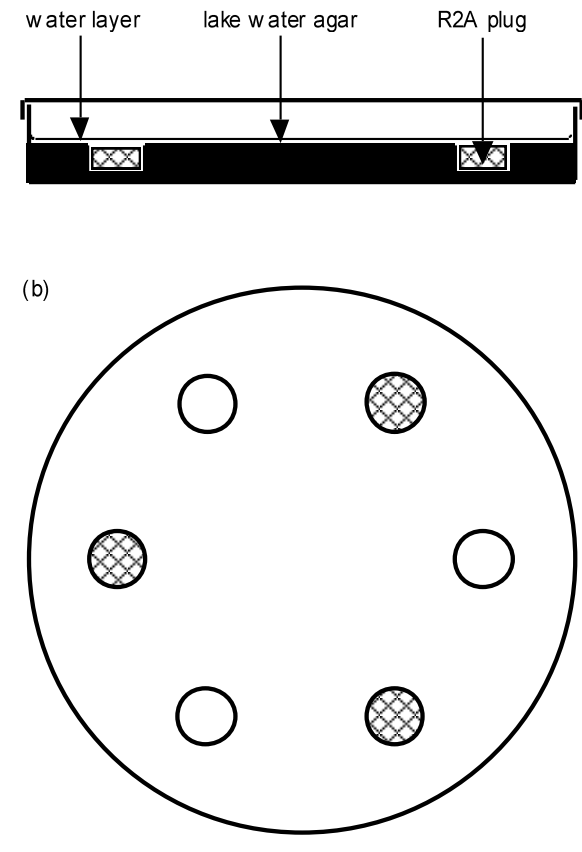
(a) Geomonhystera/

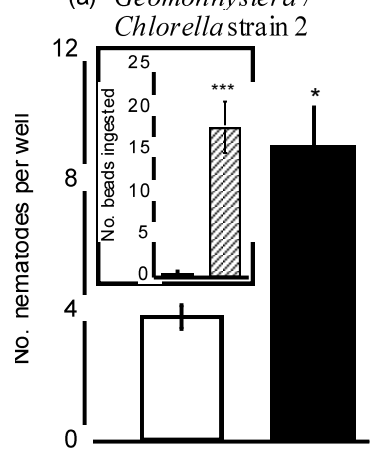

(c) Geomonhystera /

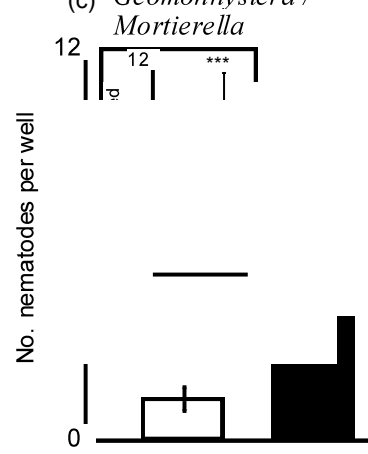

(e) Teratocephalus /

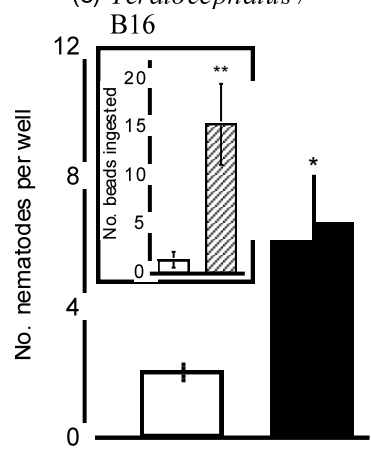

(g) Plectus

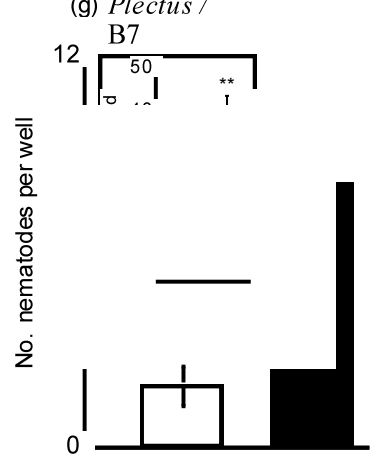

(b) Plectus /

Stichococcus

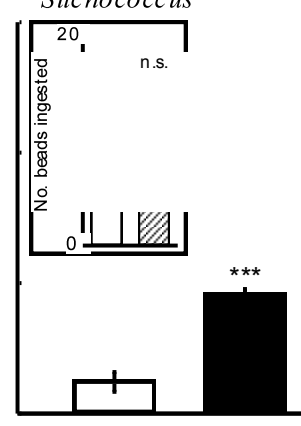

(d) Geomonhystera /

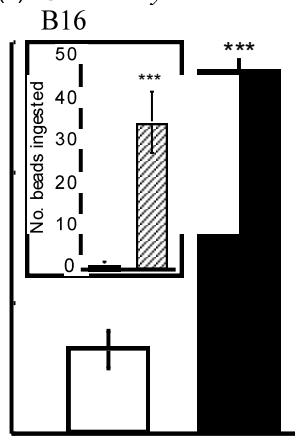

(f) Plectus /

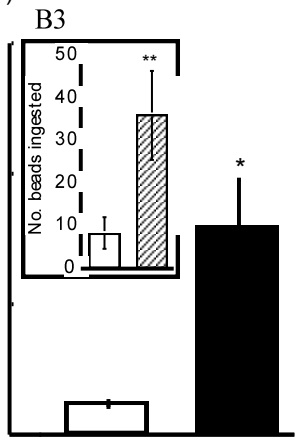

(h) Plectus /

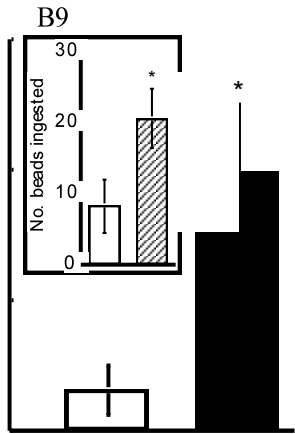

